\title{
From fighting depression to conquering tumors: a novel tricyclic thiazepine compound as a tubulin polymerization inhibitor
}

\author{
Y Mu ${ }^{1}$, Y Liu ${ }^{1}$, J Xiang ${ }^{2}$, Q Zhang ${ }^{1}$, S Zhai ${ }^{1}$, DP Russo ${ }^{3}$, H Zhu ${ }^{3,4}$, X Bai ${ }^{2}$ and B Yan ${ }^{*, 1}$
}

A novel tricyclic thiazepine derivative, 6-(p-tolyl)benzo[f] pyrido[2,3-b][1,4] thiazepine 11,11-dioxide (TBPT), exhibits potent inhibitory effects in two non-small-cell lung cancer cell lines, $\mathrm{H} 460$ and its drug-resistant variant, $\mathrm{H}_{460_{\text {TaxR }} \text {, while exhibiting much }}$ less toxic effects on normal human fibroblasts. After five injections of TBPT at a dose of $60 \mathrm{mg} / \mathrm{kg}$, it inhibits $\mathrm{H}_{460} \mathrm{TaxR}_{\text {tumor growth }}$ in xenografted mouse models by $66.7 \%$ without causing observable toxicity to normal tissues. Based on gene perturbation data and a series of investigations, we reveal that TBPT is not a P-glycoprotein substrate and it inhibits microtubule formation by targeting tubulin, thereby causing cell cycle arrest at the G2/M stage and eventually inducing apoptosis. This redeployment of antidepressant compound scaffold for anticancer applications provides a promising future for conquering drug-resistant tumors with fewer side effects.

Cell Death and Disease (2016) 7, e2143; doi:10.1038/cddis.2016.53; published online 17 March 2016

Drug resistance and nonselective toxicity have been two major clinical obstacles for cancer chemotherapy. ${ }^{1-5}$ Drug resistance is responsible for treatment failure in $>90 \%$ of patients with metastatic cancers. ${ }^{6}$ A major cause of drug resistance is the overexpression of a 170-kDa transmembrane protein, P-glycoprotein $(\mathrm{P}-\mathrm{gp})$, on the cancer cell surface in response to drug treatment. P-gp acts as an ATP-dependent drug efflux pump. ${ }^{7-9}$ Many drugs, including paclitaxel (PTX), taxanes, doxorubicin and vinca alkaloids are substrates of P-gp and are readily pumped out of cells, thereby leading to reduced drug accumulation inside cells. ${ }^{1,10}$ Furthermore, anticancer drugs often elicit serious nonselective toxicity to normal organs. Patients who have undergone chemotherapy often suffer from treatmentrelated morbidity or mortality, such as leukopenia, hepatic toxicity and even death. ${ }^{11-14}$ Therefore, potent and selective agents against multidrug-resistant cancers are urgently needed.

Tricyclic azepine derivatives, such as tianeptine, clomipramine and quetiapine, have been used as anti-psychotic drugs. Other reports have demonstrated that tricyclic azepine derivatives such as nevirapine work as anti-human immunodeficiency virus agents. ${ }^{15,16}$ A recent report has also demonstrated that tricyclic anti-depressants such as clomipramine exhibit anticancer activity. ${ }^{17}$ In this work, we report the good activity and superb selectivity of a tricyclic thiazepine compound, 6-(p-tolyl)benzo[f] pyrido[2,3-b][1,4] thiazepine 11,11-dioxide (TBPT) against drug-resistant non-small-cell lung cancer (NSCLC). TBPT inhibited the growth of both drugsensitive and drug-resistant human lung cancer cells in vitro and drug-resistant tumors in vivo without obvious side effects.
Further examination indicated that TBPT evaded the P-gpmediated drug efflux and acted as a novel microtubule depolymerizing agent, thereby inducing cancer cell G2/M phase arrest and apoptosis.

\section{Results}

Selective cytotoxicity against $\mathrm{H}_{460}{ }_{\text {TaxR }}$ and $\mathrm{H} 460$ cells. Tricyclic azepine derivatives were bioactive for several diseases, especially depression (Figure 1a). ${ }^{15-17}$ In an effort to redeploy anti-depressant compound scaffold for anticancer applications, we synthesized a series of 27 novel tricyclic thiazepine derivatives ${ }^{18}$ and screened these compounds against the NSCLC cell line $\mathrm{H} 460$ and its drug-resistant variant $\mathrm{H} 460_{\text {TaxR }}$ (manuscript submitted). ${ }^{19-21}$ The drugresistant $\mathrm{H}_{460} 0_{\text {TaxR }}$ cell line was obtained by treating $\mathrm{H} 460$ cells initially with $5 \mathrm{nM}$ PTX and increased doses up to $100 \mathrm{nM}$, leading to a remarkable overexpression of P-gp (245-folds, Figure 1b) among other possible alterations. Compared with $\mathrm{H} 460, \mathrm{H}_{460} 0_{\operatorname{TaxR}}$ is highly resistant to many clinical drugs, including PTX, vincristine and doxorubicin, because of the drug pump P-gp (Figure 1c, Supplementary Table S1). In contrast, 1 of the 27 derivatives, TBPT, exhibited the most potent cancer cell inhibitory activity with a half maximal effective concentration $\left(E_{50}\right)<0.5 \mu \mathrm{M}$ against both $\mathrm{H}_{460} 0_{\text {TaxR }}$ and $\mathrm{H} 460$ cells, whereas exhibiting minimal toxicity toward normal human fibroblasts (NHFBs; $\mathrm{EC}_{50}>100 \mu \mathrm{M}$; Figure 1d). These results showed the cytoselective anticancer activity of this compound.

\footnotetext{
${ }^{1}$ School of Chemistry and Chemical Engineering, Shandong University, Jinan, Shandong, China; ${ }^{2}$ The Center for Combinatorial Chemistry and Drug Discovery of Jilin University, The School of Pharmaceutical Sciences and The College of Chemistry, Jilin University, Changchun, Jilin, China; ${ }^{3}$ The Rutgers Center for Computational and Integrative Biology, Camden, NJ, USA and ${ }^{4}$ Department of Chemistry, Rutgers University, Camden, NJ, USA

*Corresponding author: B Yan, School of Chemistry and Chemical Engineering, Shandong University, 27 Shanda Nanlu, Jinan 250100, China. Tel: +86 531 88380019; Fax: +86 531 88380029; E-mail: drbingyan@yahoo.com

Abbreviations: P-gp, P-glycoprotein; PTX, paclitaxel; NSCLC, non-small-cell lung cancer; NHFB, normal human fibroblast; DMSO, dimethyl sulfoxide; EC ${ }_{50}$, half maximal effective concentration; $I_{50}$, half maximal inhibitory concentration; CCCP, carbonyl cyanide m-chlorophenylhydrazone; TGl, tumor growth inhibition

Received 03.10.15; revised 17.1.16; accepted 17.2.16; Edited by M Agostini
} 
a
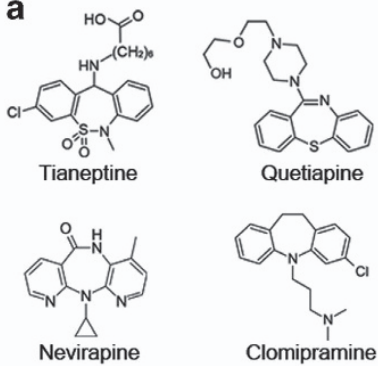

C

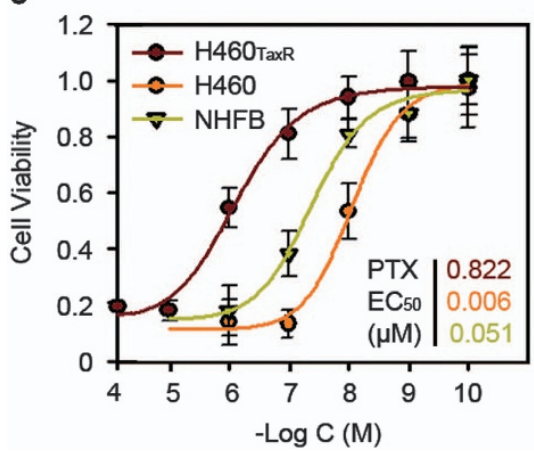

b

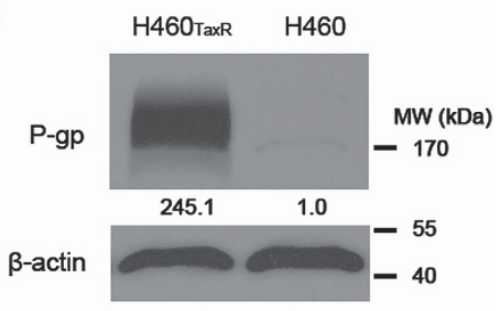

d

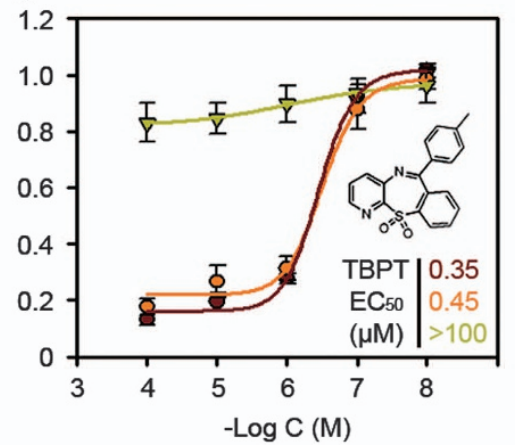

Figure 1 (a) The representative structures of bioactive tricyclic derivatives reported previously. (b) The P-gp expression in H460TaxR and $\mathrm{H} 460 \mathrm{cells}$. (c and d) The dosedependent cytotoxicity of PTX or TBPT. The cytotoxicity of PTX (c) or TBPT (d) were analyzed in NSCLC cell lines H460 TaxR, $\mathrm{H} 460$ and normal fibroblasts cell line NHFB ( $N=3$ ). The $\mathrm{EC}_{50}$ of compounds were shown in the corresponding colors of cell lines

Table 1 Drug-like properties predicted by in vitro assays ${ }^{a}$

\begin{tabular}{lcc}
\hline ADME assays & TBPT & Criterion \\
\hline PAMPA Pe $\left(10^{-6} \mathrm{~cm} / \mathrm{s}\right)$ & $1081.1 \pm 30.2$ & $>200$ \\
Caco-2 $\mathrm{P}_{\text {app }} \mathrm{A} / \mathrm{B}(\mathrm{nm} / \mathrm{s})$ & $344.79 \pm 20.6$ & $\mathrm{NA}$ \\
Caco-2 $\mathrm{P}$ app $\mathrm{B} / \mathrm{A}(\mathrm{nm} / \mathrm{s})$ & $206.23 \pm 70.05$ & $\mathrm{NA}$ \\
Efflux ratio (B2A/A2B) & $0.59 \pm 0.17$ & $<2$ \\
$\mathrm{~T}_{1 / 2}$ in human liver microsome & $5.18 \pm 0.69 \mathrm{~h}$ & $0.1-24 \mathrm{~h}$ \\
$\mathrm{~T}_{1 / 2}$ in human plasma & $>50 \mathrm{~h}$ & $>24 \mathrm{~h}$ \\
Plasma protein binding & $98.36 \pm 0.17 \%$ & $<99 \%$ \\
\hline
\end{tabular}

Abbreviation: NA, not applicable

The results represent the mean \pm S.D., $N \geq 2$

Drug-like properties of hits. As in vivo investigations are generally time consuming and expensive, it is advantageous to eliminate those compounds that are not suitable for animal experiments. One of the necessary steps is to screen the initial hits using assays testing their possible behaviors in vivo. To evaluate the drug-like properties of TBPT, a panel of in vitro assays was preformed (Table 1). The parallel artificial membrane permeability assay (PAMPA) was used to evaluate the cell permeability of the compounds. Compounds with a $\mathrm{Pe}>200 \mathrm{~cm} / \mathrm{s}$ are classified as highly permeable. TBPT exhibited excellent potential cell permeability. The Caco-2 assay was used to predict the oral absorption values of the compounds in vivo. Compounds with a Caco-2 efflux ratio $>2$ may be subject to active efflux and should not be developed further. TBPT had an efflux ratio of $0.4-0.8$. The half-life $\left(T_{1 / 2}\right)$ in human liver microsomes is used to predict the metabolism properties of compounds in vivo. A very small
$T_{1 / 2}$ suggests quick metabolism in the liver, and compounds with small values should be avoided. A very long $T_{1 / 2}(>24 \mathrm{~h})$ increases the risk of cumulative toxicity and is not desirable. TBPT exhibited suitable $T_{1 / 2}$ values in liver microsomes. $T_{1 / 2}$ in plasma indicates the stability of the drug in human blood; the high $T_{1 / 2}$ values of these compounds indicated better stability in vivo. Plasma protein binding influences the distribution of drugs into body tissues, and compounds with high plasma protein binding (>99\%) are limited in terms of the amount of free compound that are available to act on the targeted tissue. As indicated in Table 1, TBPT exhibited overall suitable drug-like properties.

Inhibition of the growth of NSCLC xenografts in mice without appreciable toxicity to normal tissues. Based on cell inhibition data, TBPT was then investigated for its tumor inhibitory property in mouse models. Five doses of TBPT (60 or $30 \mathrm{mg} / \mathrm{kg})$ or four doses of PTX $(10 \mathrm{mg} / \mathrm{kg})$ were administered every other day to $\mathrm{H} 460_{\operatorname{TaxR}}$ or $\mathrm{H} 460$ xenografted mice. Owing to drug resistance in $\mathrm{H} 460_{\text {TaxR }}$ tumors, PTX exhibited less tumor inhibitory effect in $\mathrm{H}^{460_{\text {TaxR }}}$ model (tumor growth inhibition, $\mathrm{TGI}=42.0 \%$ ) compared with that in H460 model $(\mathrm{TGI}=66.2 \%)$. Application of PTX, however, caused significant decreases of white blood cells, red blood cells and body weights of the mice, which indicated a systematic toxicity. Hepatocyte necrosis was also observed in the livers of mice treated with PTX (Figures 2 and 3). Five injections of TBPT $(60 \mathrm{mg} / \mathrm{kg})$ caused similar TGI in both $\mathrm{H} 460_{\text {TaxR }}$ and $\mathrm{H} 460$ tumors (TGI values of $66.7 \%$ and $62.9 \%$, respectively), whereas TBPT did not exhibit evident toxicity to normal tissues based on toxicity indicators, such as blood 
a

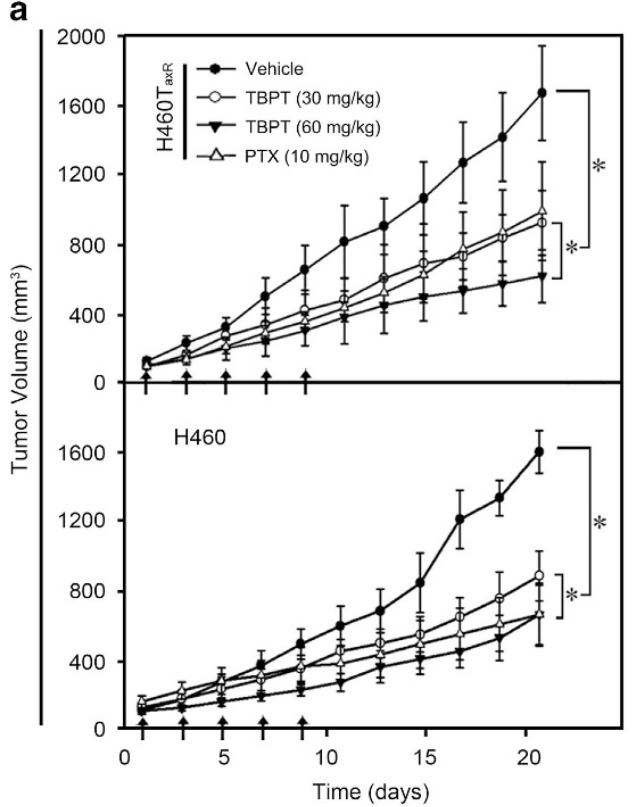

C

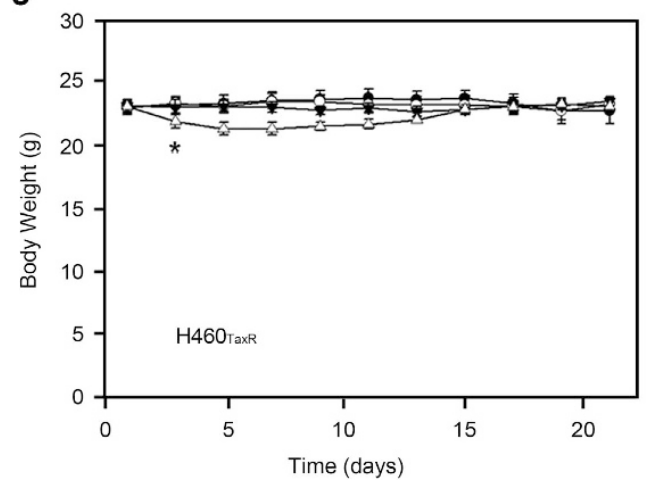

b

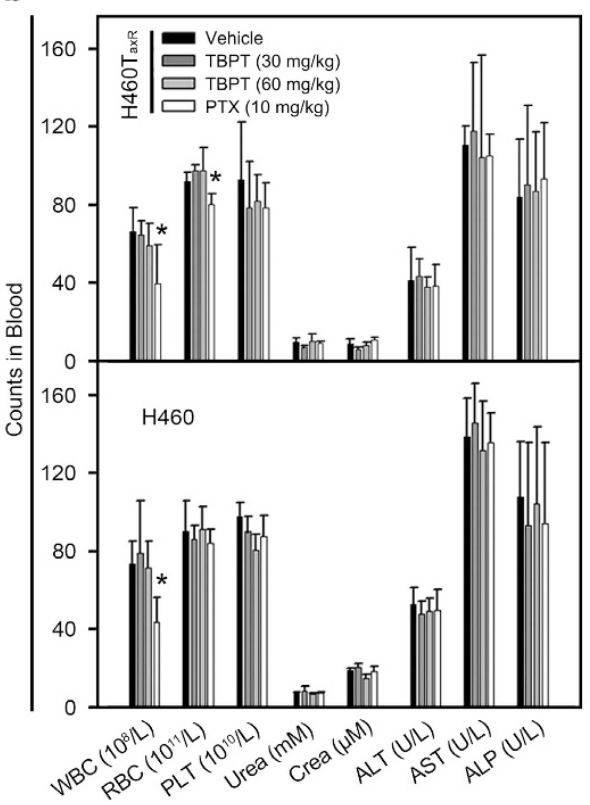

d

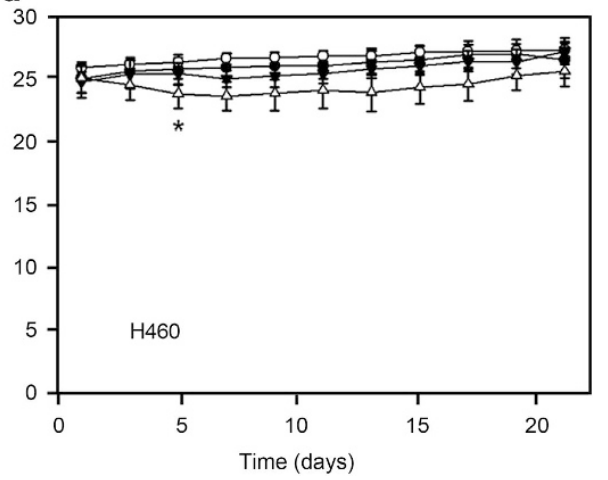

Figure 2 TGI by TBPT in $\mathrm{H}_{460} \mathrm{TaxR}_{\mathrm{R}}$ and $\mathrm{H} 460$ xenograft mouse models. Five injections of vehicle and TBPT ( $30 \mathrm{or} 60 \mathrm{mg} / \mathrm{kg}$ ) were administered intravenously at days $1,3,5$, 7 and 9 (arrows). Four injections of PTX (10 mg/kg) were administered intravenously at days 1, 3, 5 and 7. (a) The tumor volume was measured every other day. When the tumor volume in the solvent-treated group exceeded $1500 \mathrm{~mm}^{3}$, the experiment was terminated. (b) Blood biochemical and hematological analyses. (c) The body weights of the mice were monitored every other day during the experiments. ${ }^{*} P<0.05$, Student's $t$-test with day $0, N=5$

biochemical and hematological analyses, body weight change (Figure 2), relative organ weights (Supplementary Figure S1) and histopathological examination of the major organs (Figure 3). Taken together, these results show that TBPT-induced potent tumor inhibitory effects in $\mathrm{H} 460$ xenografts and drug-resistant $\mathrm{H}_{460} 0_{\mathrm{TaxR}}$ xenografts without obvious side effects. The drugs of clinical chemotherapy, such as PTX, carboplatin and vincristine, generally lead to systematic toxicity, including appetite loss, sensory neuropathy, hematologic toxicity, hepatic/renal toxicity and even death. ${ }^{11-14,22-24}$ The superb tumor selectivity of TBPT in vitro and in vivo indicated that it might cause less toxicity when applied in clinical.

TBPT is not a P-gp substrate. To determine how TBPT overcomes the drug resistance of $\mathrm{H}_{460} 0_{\text {TaxR }}$ tumors, we investigated whether TBPT was a substrate of $\mathrm{P}$-gp using a
P-gp ATPase activity assay. Substrates of P-gp, such as verapamil, typically stimulate P-gp ATPase activity. ${ }^{25,26}$ Compared with the negative control dimethyl sulfoxide (DMSO), verapamil increased the activity of P-gp ATPase by approximately threefold, whereas TBPT did not induce P-gp ATPase activity (Figure 4). These results showed that TBPT was not a substrate of P-gp and was not subjected to being transported outside. This finding explains why TBPT maintains potent inhibitory activity in drug-resistant $\mathrm{H}_{460} 0_{\mathrm{TaxR}}$ cells and tumors. Substrates of P-gp are structurally diverse, including many anticancer drugs, ${ }^{8}$ HIV protease inhibitors ${ }^{27}$ and cardiovascular drugs. ${ }^{28}$ There is still no clear understanding on common structure features of P-gp substrate. However, from experimental screening and testing, compounds like thiazolidinone and TBPT are discovered to escape P-gp transport. ${ }^{29-32}$ Such compounds with anticancer activity may help overcome drug resistance in chemotherapy of cancers. 
TBPT-induced perturbation of gene expression in $\mathrm{H}^{460_{\text {TaxR }}}$ cells. Although TBPT is not a substrate of P-gp and is allowed to maintain a high concentration inside drugresistant cancer cells, its cellular target(s) remain unknown.
To explore the possible targets of TBPT, we determined the global gene expression profile of $\mathrm{H}_{460_{\operatorname{TaxR}}}$ cells after TBPT treatment using an Agilent whole-human genome oligo microarray platform. ${ }^{20}$ The microarray analysis revealed that

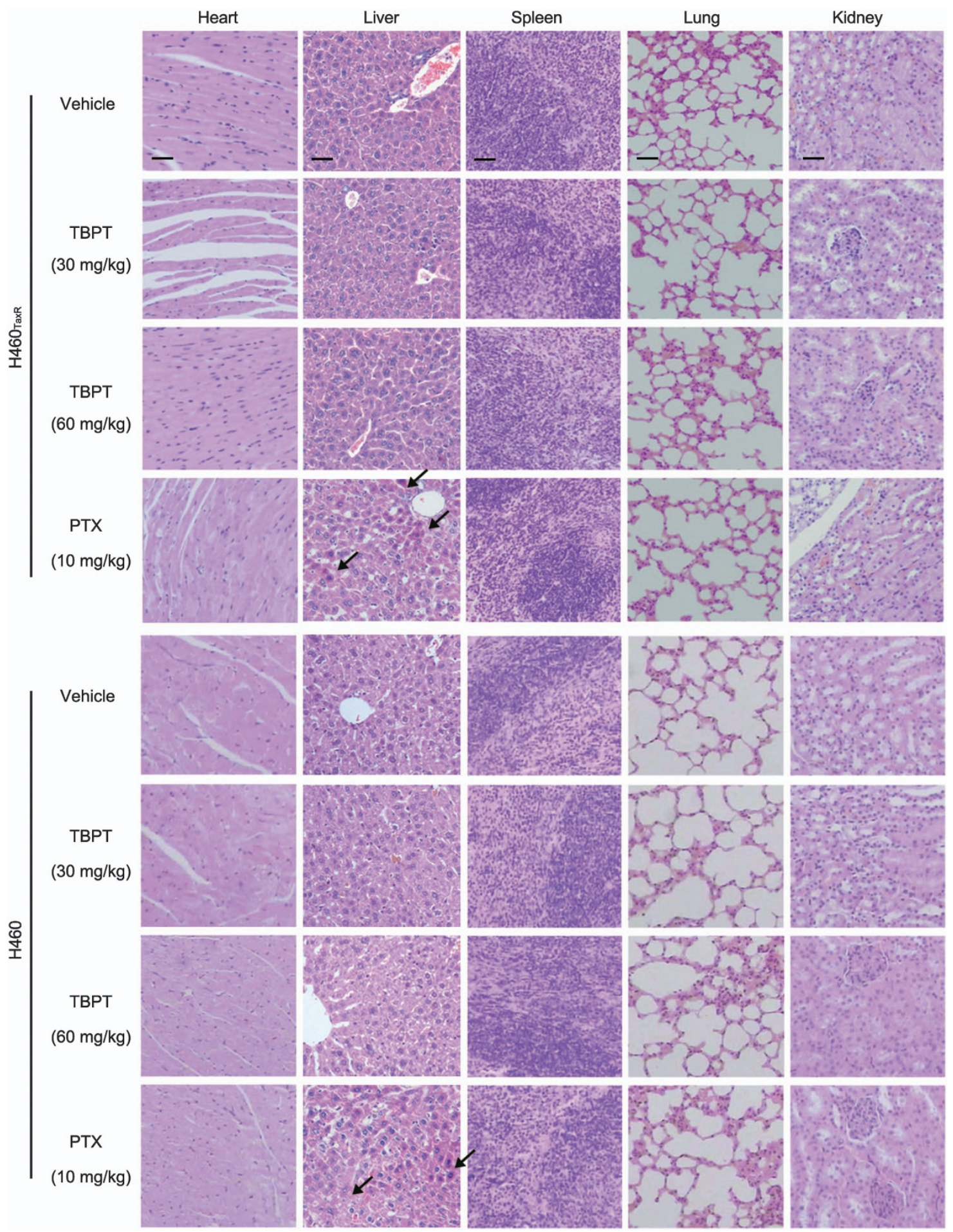

Figure 3 Histopathological examination of the major organs from TBPT or PTX-treated mouse tumor at the end of the experiments. The cross-sections of organs were stained with hematoxylin-eosin. No pathological changes were observed in any group of TBPT-treated mice. Hepatocyte necrosis was observed in some areas in the livers of PTX-treated mice (arrows). The scale bars represent $50 \mu \mathrm{m}$ and are uniform in each column 


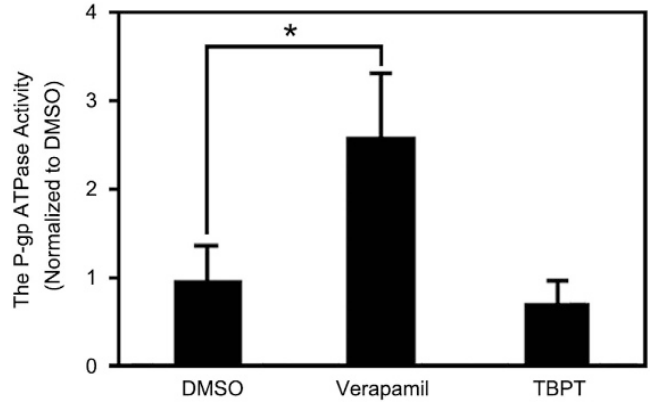

Figure 4 TBPT is not a P-gp substrate. The P-gp ATPase activity was determined in human cell membrane P-gp fractions using a luminescence-based assay. Verapamil, a known P-gp substrate, was used as a positive control and increased P-gp ATPase activity significantly. $N=3$

534 genes were suppressed and 410 genes were upregulated ( $\geq 2$-fold) in $\mathrm{H}_{460_{\text {TaxR }}}$ cells following TBPT treatment $(2 \mu \mathrm{M}, 4 \mathrm{~h})$. The gene ontology analysis indicated that genes involved in regulating microtubule cytoskeleton and nucleus functions were altered by TBPT (Supplementary Table S2). The corresponding affected biological processes included microtubule cytoskeleton organization, microtubule-based movement, spindle localization, mitotic cell cycle process, chromosome segregation and DNA/RNA metabolic processes (Supplementary Table S2). Moreover, because TBPT shares a similar scaffold with tricyclic anti-depressant drugs, it also upregulated neurological system process genes, such as GNAT1, NPAS3, GSX2 and SCN8A (Supplementary Table S2). These results suggested that TBPT might influence the microtubule organization process.

TBPT inhibited tubulin polymerization in a cell-free system and in live cells. To confirm the DNA array analysis findings, we first assessed the effect of TBPT on tubulin polymerization in a cell-free system ${ }^{33}$ using the well-known microtubule depolymerizing agent colchicine and stabilizing agent PTX as positive controls and DMSO as negative control (Figure 5a, Supplementary Figure S2). The results showed that alpha- and beta-tubulin subunits dimerized and self-assembled to form microtubules in a time-dependent manner after DMSO treatment, as indicated by a steady increase in fluorescence (Figure 5a). Colchicine caused strong inhibition of microtubule formation, with a half maximal inhibitory concentration $\left(\mathrm{IC}_{50}\right)$ value of $4.1 \mu \mathrm{M}$. TBPT also inhibited the formation of microtubules, with an $\mathrm{IC}_{50}$ value of $12.6 \mu \mathrm{M}$ (Figure $5 \mathrm{~b}$ ).

As inhibition of tubulin polymerization may cause microtubule disruptions, we next evaluated microtubule organization in live cancer cells. As shown in Figure 5c, fluorescence-labeled microtubules normally display a shape of straight lines in both NSCLC cell lines treated with DMSO (left column). After treatment with TBPT, microtubule damage, such as disordered microtubule fragments, were detected in both drug-sensitive and drug-resistant NSCLC cells (middle column). This damage was similar to that caused by the tubulin inhibitor colchicine (right column).

To better understand how TBPT interacts with tubulin, the molecular docking of TBPT to the colchicine-binding site of the tubulin crystal structure (1SA0) was performed using the triangle matcher placement algorithm. TBPT exhibited good matching with the colchicine-binding site, with a docking $S$ score of -5.69 , which was extremely close to that of colchicine (-6.02). As shown in Figure 5d, TBPT (fuchsia) overlapped well with colchicine (blue) in the docking model. It was indicated that TBPT might bind with tubulin at or near the colchicine-binding site.

These results and results from the previous section demonstrated that TBPT functions as a inhibitor for tubulin polymerization. Microtubule-targeting agents work as antimitotic agents, causing cell cycle arrest and apoptosis. ${ }^{34}$ However, most known microtuble-targeting agents, such as PTX ${ }^{35}$ vinca alkaloids ${ }^{36}$ and colchicine, ${ }^{37}$ exhibit intense dose-limiting toxicity with narrow therapeutic window. Microtubule-targeting agent TBPT, with a much lower toxicity, is a promising starting point for developing of a new generation of anticancer agents.

TBPT-induced G2/M arrest and apoptosis in NSCLC cells. Microtubule-targeting agents suppress microtubule dynamics, resulting in mitotic arrest and apoptosis. ${ }^{38}$ As shown in Figure 6a, strong G2/M arrest (over $80 \%$ cells) was detected in both $\mathrm{H} 460_{\mathrm{TaxR}}$ and $\mathrm{H} 460$ cell lines after $12 \mathrm{~h}$ of TBPT treatment. Consistent with this finding, p21 (waf1/cip1), a well-known cell cycle progression inhibitor, was significantly upregulated in TBPT-treated cells (Figure 6b).

Moreover, approximately $50 \%$ of the NSCLC cells were in an apoptotic/necrotic state after a 48-h treatment with TBPT $(2 \mu \mathrm{M}$; Figure $7 \mathrm{a})$. To further elucidate TBPT-mediated apoptosis pathways, we examined the activities of caspases 8,9 and $3 / 7$ after TBPT treatment. As shown in Figures $7 \mathrm{~b}$ and c, TBPT treatment activated caspases 8,9 and $3 / 7$ in a timedependent manner in both $\mathrm{H}_{460} 0_{\text {TaxR }}$ and $\mathrm{H} 460$ cell lines. This result indicates that the TBPT-induced cell apoptosis was the result of activating both extrinsic and intrinsic apoptosis pathways. To validate the occurrence of apoptosis, we also observed the cleavage of PARP and a decrease in the mitochondrial membrane potential after TBPT treatment (Figures 7c and d). In short, TBPT selectively induced G2/M cell cycle arrest and apoptosis in both $\mathrm{H} 460_{\mathrm{TaxR}}$ and $\mathrm{H} 460$ cells, which is consistent with the anticancer mechanisms of other reported microtubule-targeting agents, including nocodazole and PTX. ${ }^{39-45}$ In contrast, TBPT-induced very little cell cycle arrest or apoptosis in NHFB cells and mice hippocampus cells (Supplementary Figures S3 and S4), which is consistent with the observed low cytotoxicity to NHFB cells. Beside TBPT, there are other less toxic microtubule-targeting agents reported with unknown mechanism. ${ }^{32,46}$

The likely mechanism of the low toxicity of TBPT to normal cells and organs. Tubulin molecules exist in both cancer and normal cells. However, TBPT selectively inhibits the growth of cancer cells or tumors. Studies have shown that a rapid rate of cell division and a higher turnover of active tubulin dynamics in cancer cells make them acutely sensitive to anti-tubulin drugs. ${ }^{40,47}$ The moderate inhibitory ability of TBPT against tubulin polymerization $\left(\mathrm{IC}_{50}=12.6 \mu \mathrm{M}\right)$ may maintain cancer inhibition because of its higher microtubule dynamics and exhibit less toxicity to normal cells because of 

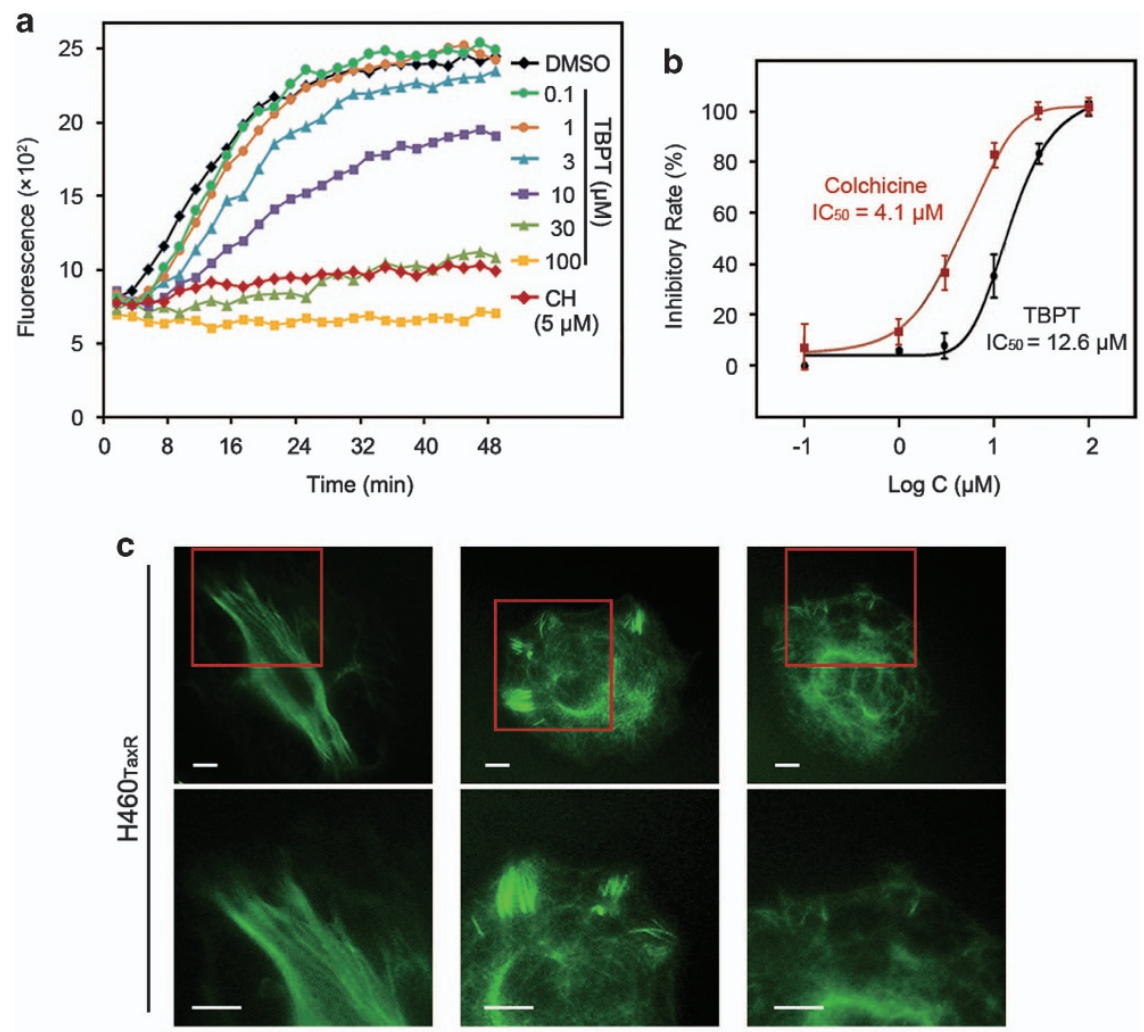

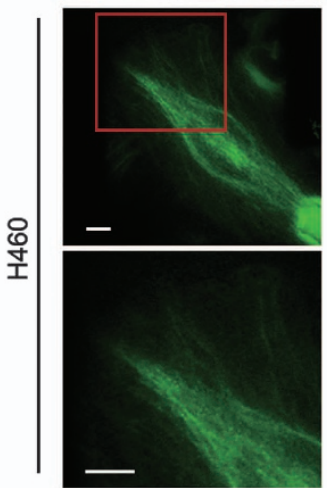

DMSO

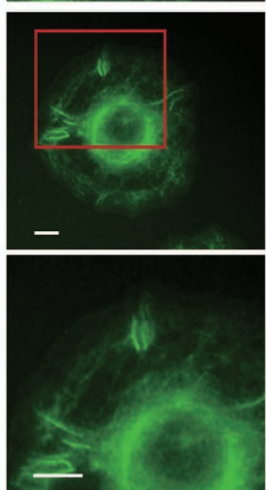

TBPT

$(2 \mu \mathrm{M})$

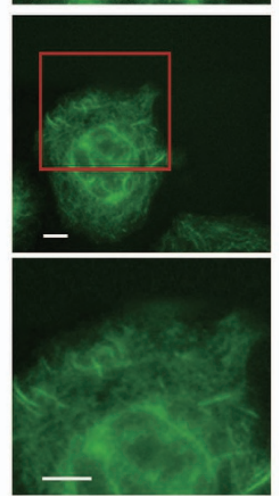

Colchicine

(Positive Control)

d

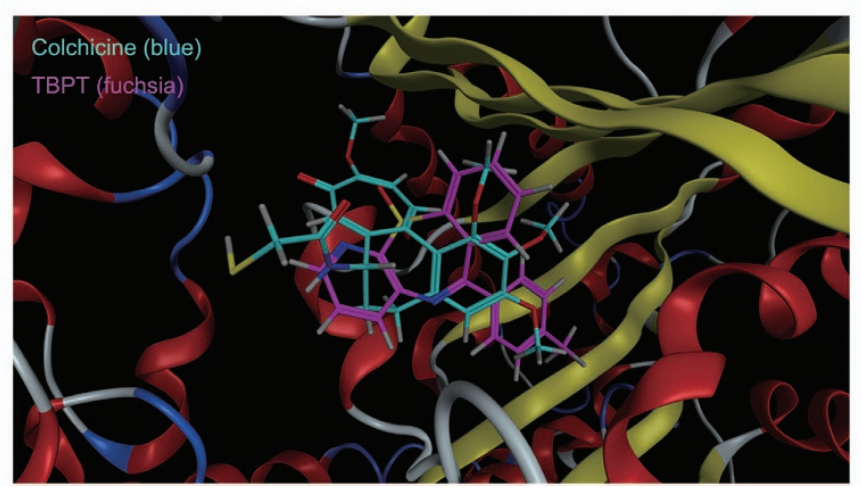

Figure 5 TBPT inhibited tubulin polymerization and disrupted microtubule formation. (a) The rate of the tubulin polymerization process was monitored via fluorescence in the presence of TBPT or colchicine $(\mathrm{CH})$ at the indicated concentration in a cell-free system. The fluorescence was monitored every $2 \mathrm{~min}$ for $50 \mathrm{~min}$. (b) Dose-dependent tubulin polymerization was observed. $N=2$. (c) After the cells were treated with DMSO, TBPT or $\mathrm{CH}$ for $24 \mathrm{~h}$, their cellular microtubules were visualized via green fluorescence using a fluorescent secondary antibody binding specifically to anti- $\alpha$-tubulin antibody. The scale bars represent $10 \mu \mathrm{m}$. (d) The molecular docking study of TBPT to the CH-binding site of tubulin 
a TBPT $(2 \mu \mathrm{M})$
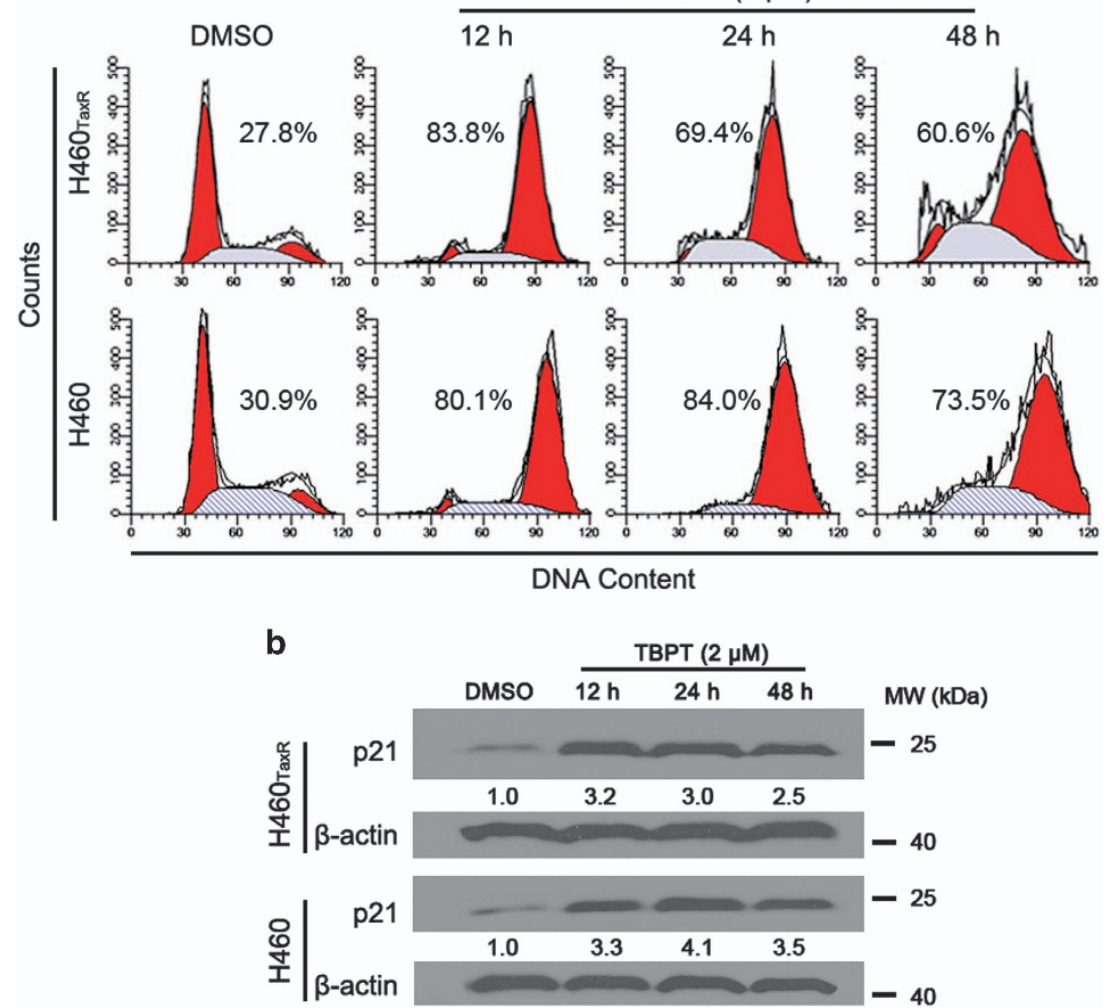

Figure 6 Analyses of the cell cycle and p21 expression in $\mathrm{H} 460_{\text {TaxR }}$ and $\mathrm{H} 460$ cells after TBPT treatment. NSCLC cells were treated with DMSO or TBPT (2 $\left.\mu \mathrm{M}\right)$ for the indicated times. (a) Cells were stained with PI and analyzed via flow cytometry. The two red peaks indicate the cells in the G1 and G2/M phases, respectively. The middle gray area indicates the cells in the S phase of the cell cycle. The ratio of cells in the G2/M phase is also shown. (b) Western blot analysis of p21 expression in NSCLC cells

their low microtubule dynamics. ${ }^{21}$ In addition, other targets of TBPT that account for its selective anticancer activity may also exist. For example, TBPT significantly suppressed a series of genes involved in DNA double-strand break repair, including LIG4, CENPF, DNAJC2, RECQL, SMC6 and BRCA2 ( $\geq$ 2-fold; Supplementary Table S2), which are also considered vital targets for treating cancer cells without affecting normal cells. ${ }^{48,49}$

In addition, off-target effects of drugs, which are caused by interactions between drugs and unintended targets or signaling pathways, can also disrupt normal functions of cells and cause nonselective drug toxicity. ${ }^{50-53}$ In eukaryote cells, almost all signaling pathways are mediated by protein kinases, which constitute the largest functional protein family. ${ }^{54}$ Unintended inhibition of protein kinases may help the anticancer activity of TBPT but can also lead to serious nonselective drug toxicities. ${ }^{55-57}$ To further evaluate the offtarget effects of TBPT, we next assessed the ability of TBPT to inhibit a panel of 442 human kinases (covering $80 \%$ of the human protein kinome) at 5 and $10 \mu \mathrm{M}$ using a kinome scanning platform. ${ }^{58,59}$ TBPT exhibited negligible binding affinity to or inhibitory activity against the 442 human kinases (Figure 8, Supplementary Table S3). ${ }^{60-62}$ This result further accounted for the lack of off-target effect of TBPT. Therefore, TBPT is a very selective tubulin polymerization inhibitor.

\section{Discussion}

P-gp-independent anticancer activity of TBPT. In this study, we reported that TBPT exhibited potent anticancer activity in drug-resistant $\mathrm{H}_{46} 0_{\text {TaxR }}$ cell line and mice tumor. We revealed that TBPT is not a substrate of P-gp, a major origin of multidrug resistance. This provides the basis for TBPT to enter cancer cells and provides a key explanation for its P-gp-independent anticancer activity. Indeed, there are many other mechanisms of cancer cells to induce drug resistance besides $\mathrm{P}$-gp. ${ }^{1,63}$ TBPT can overcome the P-gpmediated drug resistance. This does not mean that TBPT is bioactive for all cancer cells with other drug-resistant mechanisms. However, TBPT has removed the major barrier (P-gp) to interact with cancer cells, which is an advantage compared with other drugs.

Low toxicity of TBPT in vitro and in vivo. TBPT exhibited less toxicity to NHFBs compared with cancer cells. Furthermore, no obvious toxicity was found in TBPT-treated mice compared with PTX-treated mice. PTX caused significant decreases of white blood cells, red blood cells and body weights of the mice, which indicated a systematic toxicity. And considering that serious toxicities were detected during PTX treatment, we decreased the drug doses to four injections. TBPT shares a similar scaffold with tricyclic anti- 
a

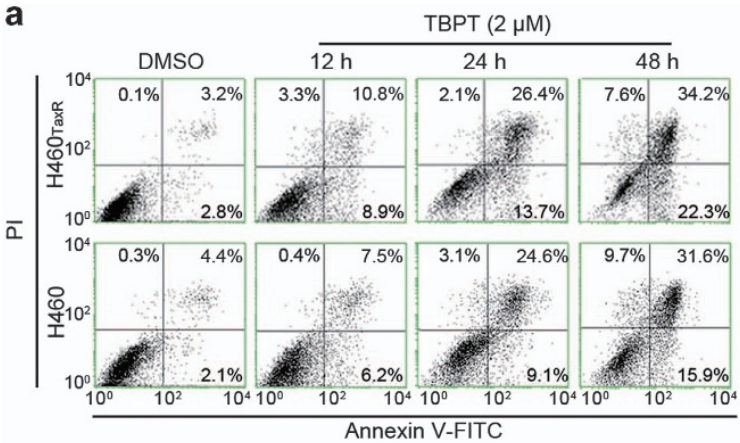

b

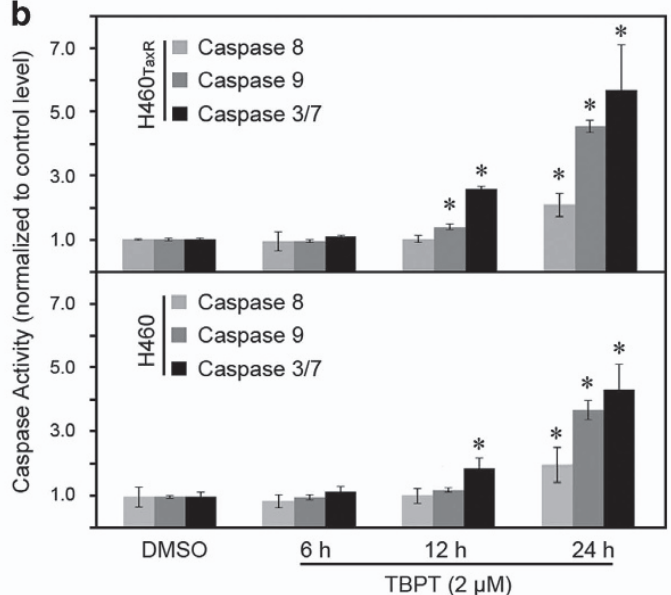

C

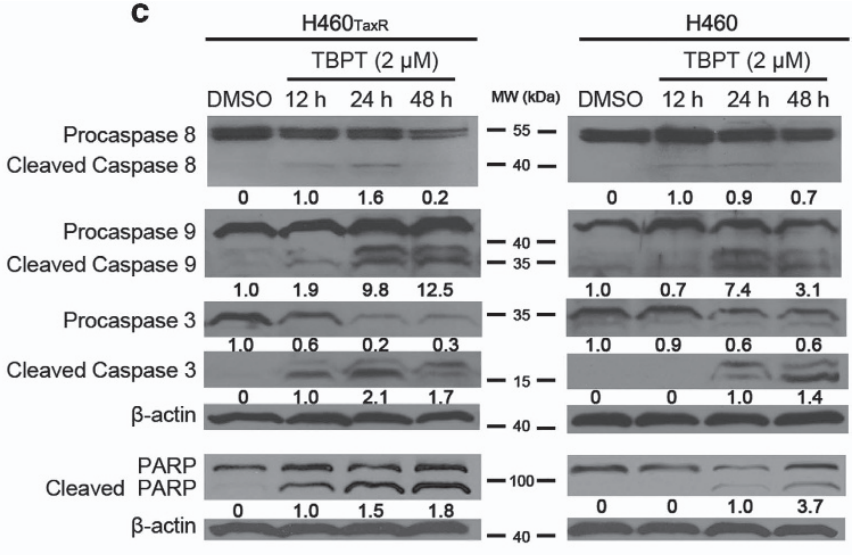

d

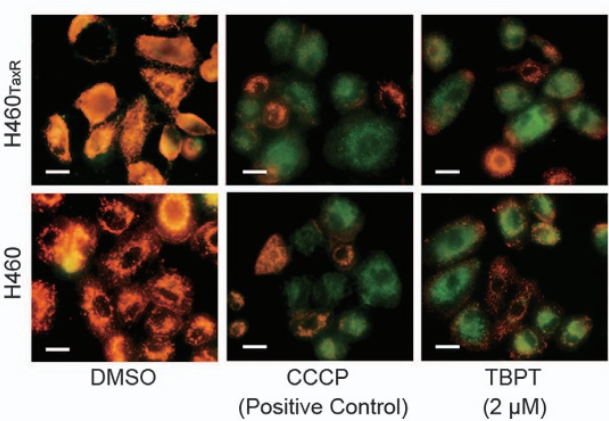

Figure 7 TBPT induces time-dependent apoptosis in both $\mathrm{H}_{460} \mathrm{TaxR}_{\mathrm{T}}$ and $\mathrm{H} 460$ cells. (a) The cells were treated with DMSO or TBPT (2 $\left.\mu \mathrm{M}\right)$, stained with PI/Annexin V-FITC, and analyzed using flow cytometry. (b) The activities of caspases 8,9 and $3 / 7$ were examined using a fluorescence-based assay. * ${ }^{*}$ tudent's $t$-test with the DMSO group, $P<0.05$, $N=3$. (c) Western blot analysis of caspases 8, 9, 3 and PARP after TBPT treatment in NSCLC cells. (d) The mitochondrial membrane potential was determined using JC-1 dye, and a well-known mitochondrial uncoupler, CCCP, was used as a positive control. Scale bar, $20 \mu \mathrm{m}$. Healthy cells maintain a high mitochondrial membrane potential and emit red fluorescence, whereas apoptotic cells have a low mitochondrial membrane potential and emit green fluorescence. The mitochondrial membrane potential decreased significantly in NSCLC cells treated with TBPT

depressant drugs. In addition, it also affected several neurological system process genes, such as GNAT1, NPAS3, GSX2 and SCN8A. But no obvious abnormal behaviors of mice were observed during TBPT treatment. Also, TBPT did not show toxic effects in mice hippocampus cells, based on cell cycle and apoptosis analysis, which indicated that TBPT might have little neurotoxicity when applying in human.

We found that TBPT interacted with tubulin dynamics, which is ubiquitous throughout all animal cells, but TBPT did not cause obvious toxicity. We speculate that TBPT may benefit from its moderate tubulin inhibitory effect, which may not be enough to inhibit normal cells with lower tubulin dynamics (less target concentration) but is lethal to cancer cells with much more active tubulin dynamics (more target concentration). TBPT also benefits from its much less off-target effects according to the kinome assay result. In addition, there may be other critical targets besides tubulin, for example, TBPT significantly suppressed a series of genes involved in DNA double-strand break repair, which is important to selective drug toxicity. ${ }^{48,49}$

Drugs all have adverse effects, especially for anticancer drugs. We evaluated the general toxicity of TBPT to human fibroblasts and neuron-derived cells, mice body weight, blood analyses and major organs. Further adverse effects should be properly assessed in more details if taking this compound to clinic. However, based on our experimental data, we may conclude that TBPT is much safer than PTX to achieve the comparable anticancer effect.

In conclusion, we redeployed the anti-depressant tricyclic thiazepine scaffold for an anticancer application. Compound TBPT was discovered from a library of tricyclic thiazepine derivatives through a cytoselective toxicity assay. TBPT inhibited the growth of both drug-sensitive $(\mathrm{H} 460)$ and drug-resistant $\left(\mathrm{H} 460_{\operatorname{TaxR}}\right) \mathrm{NSCLC}$ cells with an $\mathrm{EC}_{50}<0.5 \mu \mathrm{M}$, whereas exhibiting less toxicity to NHFBs $\left(\mathrm{EC}_{50}>100 \mu \mathrm{M}\right)$. It inhibited the growth of both $\mathrm{H}_{460} \mathrm{TaxR}_{\mathrm{T}}$ and $\mathrm{H} 460$ tumors in xenografted mouse models by $>60 \%$ without appreciable toxicity to normal tissues. We revealed that TBPT evaded P-gp-mediated drug efflux and inhibited tubulin polymerization, leading to microtubule damage, cell cycle arrest in the G2/M phase and cell apoptosis. In conclusion, we discovered a novel tricyclic thiazepine derivative as a tubulin polymerization inhibitor exhibiting potent anticancer activity against drug-resistant NSCLC in vitro and in vivo. Our finding indicates a bright future of drug redeployment efforts and provides an effective therapeutic solution for drug-resistant tumors. 


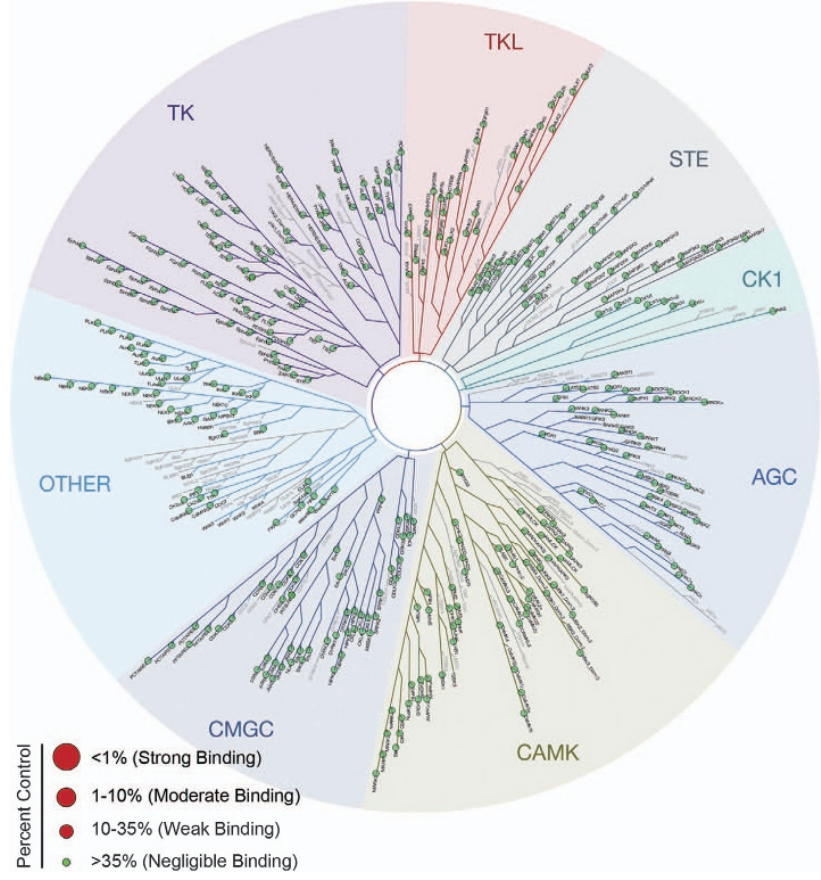

Figure 8 The ability of TBPT to bind and inhibit 442 kinases in the human kinome. TBPT was screened twice at 5 and $10 \mu \mathrm{M}$ using a kinome scanning assay. The $35 \%$ of the binding percentage of DMSO was used as the criterion of negligible binding, as suggested by the manufacturer and previous reports. ${ }^{60-62}$ If any kinase binds TBPT $(\% \mathrm{Ctrl}<35 \%)$, then a large red dot is shown in the kinome tree. The binding and inhibitory percentages for TBPT for all 442 human kinases (covering $80 \%$ of the human kinome) were greater than the criterion (35\%). The kinase groups are abbreviated as follows: TK, tyrosine kinase; TKL, tyrosine kinase-like; STE, homologs of the yeast sterile 7, 11 and 20 kinases; CK1, casein kinase 1; AGC, the protein kinase A-, G- and C-containing families; CAMK, calcium/calmodulin-dependent protein kinase; CMGC, cyclin-dependent kinase-, mitogen-activated protein kinase-, glycogen synthase kinase 3-, and dual-specificity protein kinase-containing families; OTHER, all other protein kinases that do not belong to specific groups. The detailed results are presented in Supplementary Table S3

\section{Materials and Methods}

Reagents and cell culture. All biological reagents and solvents were obtained from commercial suppliers and used as recommended. The human NSCLC cell line $\mathrm{H} 460$ and P-gp-overexpressing drug-resistant cell line $\mathrm{H}_{460} \mathrm{TaxR}_{\mathrm{R}}$ were cultured in RPMI-1640 medium supplemented with $10 \%$ fetal bovine serum, $100 \mathrm{units} / \mathrm{ml}$ penicillin and $100 \mathrm{mg} / \mathrm{ml}$ streptomycin. The NHFB cell line NHFB was cultured in DMEM with the same supplements. All cells were maintained in a $37^{\circ} \mathrm{C}$ incubator with $95 \%$ humidity and $5 \% \mathrm{CO}_{2}$.

Cell viability assay. The cell viability was determined using the sulforhodamine B assay. ${ }^{64}$ In brief, cells (4000 cells in $100 \mu$ l medium) were seeded in 96-well culture plates and incubated for $24 \mathrm{~h}$. The cells were treated with the compounds or with an equal volume $(0.1 \%)$ of DMSO for $72 \mathrm{~h}$. The cell viability was calculated using the following formula: cell viability $=A_{\text {treatment }} / A_{\text {control. }}$. The $\mathrm{EC}_{50}$ values were determined using the Sigma Plot 10.0 software package (Systat Software Inc., San Jose, CA, USA).

In vitro drug properties assays. The PAMPA and Caco-2 cell bi-directional transport assay of the derivatives were conducted as described in our previous report. ${ }^{65,66}$ The human liver microsome, plasma stability and plasma protein-binding assays were conducted following modified protocols reported by Cyprotex (Macclesfield, UK). ${ }^{67-70}$

In vivo experiments. NSCLC xenograft tumor models were constructed as reported previously. ${ }^{20,21}$ Four-week-old female athymic nude mice were purchased from Vital River Laboratory Animal Technology Co., Ltd (Beijing, China) and housed under pathogen-free conditions. This study was performed following the recommendations from the Guide for the Care and Use of Laboratory Animals by the National Institutes of Health. The protocol was approved by the Committee on the Ethics of Animal Experimentation of Shandong University. H460 and H460 TaxR cells $\left(5 \times 10^{6}\right.$ cells in $100 \mu$ l PBS) were injected subcutaneously into the dorsal flank of each mouse. When the tumors reached volumes of $100 \mathrm{~mm}^{3}$, the mice were divided randomly into four groups. The mice were treated every other day five times with intravenous injections of (1) vehicle (the solvent of TBPT: $60 \%$ PBS, $8 \%$ Cremophor EL, $8 \%$ EtOH, $12 \%$ poly propylene glycol and 12\% PEG-400), (2) TBPT (30 mg/kg) or (3) TBPT (60 mg/kg). Another group was treated with PTX (10 mg/kg) every other day four times as the positive control. The tumor dimensions and body weights were measured every other day. The tumor volume was calculated according to a standard formula: volume $=$ width $^{2} \times$ length/2. The experiment was terminated and the mice were killed when the tumor volumes in the solvent-treated group exceeded $1500 \mathrm{~mm}^{3}$. The mouse organs and blood were collected and used for hematoxylin-eosin staining and serum chemistry assay. TGI rates were assessed using the following formula: $T G I=1-\left(T_{t}-T_{0}\right) /\left(C_{t}-C_{0}\right) \times 100 \% . T_{t}$ and $T_{0}$ indicate the tumor volumes of the treated group at days $t$ and $0 . C_{t}$ and $C_{0}$ indicate the tumor volumes of the control group at days $t$ and 0 , respectively.

P-gp ATPase activity assay. The P-gp ATPase activity assay was conducted using the P-gp Glo Assay System following the manufacturer's protocol (Promega Biotech, Madison, WI, USA). $\mathrm{Na}_{3} \mathrm{VO}_{4}$ (a P-gp inhibitor without P-gp ATPase stimulation activity), verapamil (a P-gp substrate with ATPase stimulation activity) and DMSO (the solvent for TBPT) were used as controls. TBPT $(2 \mu \mathrm{M})$ and the control reagents were incubated with the P-gp membrane for $1 \mathrm{~h}$. Then, the luminescence was measured using a POLARstar Galaxy luminometer (BMG Labtech, Offenburg, Germany). The change in luminescence was calculated by comparing the $\mathrm{Na}_{3} \mathrm{VO}_{4}$-treated samples with the other compound-treated samples. The change in luminescence change is proportional to the ATP consumption in the samples, which correlated positively with the P-gp ATPase activity.

Genome-wide transcriptional profiling microarray. Cells $\left(1 \times 10^{6}\right.$ cells) were seeded and incubated in $10 \mathrm{~cm}$ culture plates for $24 \mathrm{~h}$. After the cells were treated with DMSO or TBPT $(2 \mu \mathrm{M})$ for $4 \mathrm{~h}$, they were washed in PBS and suspended in $1.0 \mathrm{ml}$ TRIzol reagent (Life Technologies, Grand Island, NY, USA). RNA preparation and microarray hybridization were performed according to the manufacturer's instructions (Kangchen Bio-Tech, Shanghai, China) for the Agilent Whole Human Genome Oligo Microarray Platform (Santa Clara, CA, USA). ${ }^{20}$

Tubulin polymerization assay. A fluorescence-based tubulin polymerization assay kit was used to monitor the polymerization process according to the manufacturer's instructions (Cytoskeleton, Denver, CO, USA). Briefly, after prewarming the assay plate at $37^{\circ} \mathrm{C}$ for $1 \mathrm{~min}$, DMSO (control, $0.1 \%$ ), colchicine $(5 \mu \mathrm{M})$ or TBPT $(0.1-100 \mu \mathrm{M})$ was added to each well. Tubulin solution (50 $\mu \mathrm{l})$ was dispensed rapidly into each well. Then, the fluorescence of samples in the assay plates was measured every $2 \mathrm{~min}$ for $50 \mathrm{~min}$ at $37^{\circ} \mathrm{C}$ using a 1420 Multi-label Counter (Perkin Elmer, Boston, MA, USA). The excitation wavelength was $355 \mathrm{~nm}$, and the emission wavelength was $460 \mathrm{~nm}$.

Immunofluorescence staining for microtubule structure. Cells $\left(1 \times 10^{5} / \mathrm{ml}\right)$ were seeded in 24-well culture plates and treated with DMSO, TBPT $(2 \mu \mathrm{M})$ or colchicine $(1 \mu \mathrm{M})$ on the next day for $24 \mathrm{~h}$. The cells were washed in PBS and then fixed in paraformaldehyde $(4 \% \mathrm{v} / \mathrm{v})$ for $10 \mathrm{~min}$. After the cells were washed three times in PBS, they were blocked with $5 \%$ (w/v) BSA for 30 min at RT. Then, $\alpha$-tubulin antibody (CST, Beverly, MA, USA) was incubated with cells in a humid chamber overnight at $4^{\circ} \mathrm{C}$. After the cells were washed three times in PBS, they were incubated with goat anti-rabbit IgG-FITC (Jackson ImmunoResearch, West Grove, PA, USA) for $1 \mathrm{~h}$ at $37^{\circ} \mathrm{C}$. Then, the cells were mounted with mounting medium containing DAPI (Vector Lab, Peterborough, UK) after they were washed three times in PBS. Finally, the cells were observed and imaged using a fluorescence microscope (Olympus IX71, Tokyo, Japan).

Molecular docking study. Molecular operating environment (MOE) software package (Chemical Computing Group Inc., Montréal, Quebec, Canada) was used to perform the docking study. The 2D SMILES of compounds were converted to energy-minimized $3 \mathrm{D}$ structures, and partial charges were calculated using MOE's Rebuild $3 \mathrm{D}$ procedure with a root-mean-square gradient of 0.1 in a Merck Molecular 
Force Field 94x. The 3D tubulin crystal structure of each compound was downloaded from the Protein Data Bank (ID: 1SA0). The structure was loaded into $\mathrm{MOE}$, and implicit hydrogens were added and ionization states were assigned using MOE's Protonate $3 \mathrm{D}$ procedure. The active site was defined by the formation of the co-crystalized ligand colchicine on tubulin. Compounds were docked to the active site using MOE's triangle matcher algorithm, and the poses were ranked in terms of their ASE scoring. Poses were relaxed by forcefield refinement in an AMBER94 forcefield and ranked by affinity dG score (S score). MOE's affinity dG scoring function estimates the contribution to free energy of binding from ionic, hydrophobic, or hydrogen bonds between ligand and receptor atoms. To correlate the S score to an experimentally determined conformation, the conformation closest to the crystalized structure according to the lowest root-mean-square deviation of atomic positions was chosen. The conformations for compounds were ranked in terms of their S scores and the conformation with the lowest S score was selected.

Flow cytometric analysis. Cell cycle and apoptosis analyses were performed on a Guava EasyCyte Flow Cytometry System (Millipore, Billerica, MA, USA). Cells were seeded in 6-cm culture plates and treated with $2 \mu \mathrm{M}$ TBPT or an equal volume of DMSO on the next day for the indicated times. To analyze the intracellular DNA content, cells were harvested, washed twice in PBS and fixed in $70 \%$ ethanol at $-20^{\circ} \mathrm{C}$ overnight. After the cells were washed in PBS, they were stained with Guava cell cycle reagent (Millipore) and analyzed via flow cytometry. For cell apoptosis analysis, the cells were harvested, washed in PBS, stained with PI/Annexin V-FITC reagent (Life Technologies) and analyzed by flow cytometry.

Western blot analysis. Cells $\left(1 \times 10^{6}\right.$ cells in $10 \mathrm{ml}$ medium $)$ were seeded in $10-\mathrm{cm}$ dishes. After the NSCLC cells were treated with DMSO or TBPT, they were washed and collected. Cell lysates were prepared conventionally in RIPA lysis buffer. The protein concentrations were determined using the BCA protein assay. Equal amounts of total protein were loaded onto SDS-PAGE gels (8-10\%) and transferred onto PVDF membranes. After the membranes were blocked with $5 \%$ nonfat milk for $1 \mathrm{~h}$, they were blotted with primary antibodies against P-gp, $\beta$-actin, full-length caspase 3 (Santa Cruz Biotechnology, Dallas, TX, USA), caspase 8 (BD Biosciences, San Jose, CA, USA), p21, caspase 9, cleaved caspase 3 and PARP (CST) at $1: 500-1: 1000$ dilution overnight at $4^{\circ} \mathrm{C}$. Then, the membranes were incubated with goat anti-mouse or goat anti-rabbit secondary antibodies (1:5000, Santa Cruz) at RT for $1 \mathrm{~h}$. An enhanced chemiluminescence western blot system (Millipore) was used to detect the immunoreactive bands. Intensity of the blot was determined using the ImageJ software (NIH, Bethesda, MD, USA).

Caspases activity assay. The activities of caspases 8,9 , and $3 / 7$ in $\mathrm{H}_{460} \mathrm{TaxR}_{\mathrm{R}}$ and $\mathrm{H} 460$ cells were examined via a fluorescence-based assay using Caspase-Glo 8, Caspase-Glo 9 Assay kits and Apo-ONE Homogeneous Caspase$3 / 7$ Assay Kit (Promega, Madison, WI, USA). Cells $\left(1 \times 10^{6}\right.$ cells in $10 \mathrm{ml}$ medium) were seeded in 10-cm dishes. After $24 \mathrm{~h}$, the cells were treated with TBPT $(2 \mu \mathrm{M})$ or DMSO for 6,12 and $24 \mathrm{~h}$. Then, the cells were washed in PBS and collected. Cell lysates were prepared conventionally in RIPA lysis buffer. Protein concentrations were determined using the BCA protein assay. Equal amounts $(10 \mu \mathrm{g})$ of total protein of samples were added to 96 -well culture plates containing $100 \mu \mathrm{l}$ caspases 8, 9 and 3/7 activity working solution. After the samples were incubated for $1 \mathrm{~h}$ at RT, the fluorescence of each well was determined at $499 \mathrm{~nm}$ with an emission wavelength of $521 \mathrm{~nm}$ using a multimode plate reader (Victor X2, Perkin Elmer, Boston, MA, USA). The fluorescence intensities are proportional to the activities of caspases 8,9 and $3 / 7$.

Mitochondrial membrane potential determination assay. The mitochondrial membrane potential was determined using JC-1 dye (Beyotime, Beijing, China). NSCLC cells $\left(4 \times 10^{4}\right.$ cells in $\left.0.5 \mathrm{ml}\right)$ were seeded in 24-well culture plates. The cells were treated with DMSO or TBPT $(2 \mu \mathrm{M})$ on the next day for $12 \mathrm{~h}$. Carbonyl cyanide m-chlorophenylhydrazone (CCCP; $10 \mu \mathrm{M}$ ), a mitochondrial membrane disrupter, was used to treat cells for $20 \mathrm{~min}$ as a positive control. Then, the cells were incubated with $200 \mu \mathrm{l} \mathrm{JC}-1$ working solution at $37^{\circ} \mathrm{C}$ for $20 \mathrm{~min}$. After the cells were washed in RPMI-1640 medium, they were observed and imaged using a fluorescence microscope (Olympus IX71).

Kinome screening assay. The binding assay for 442 non-mutant kinases was performed using KINOMEscan (DiscoveRx Corporation, Fremont, CA, USA) as reported previously. ${ }^{58,59}$ TBPT was screened at concentrations of 5 and $10 \mu \mathrm{M}$ to identify the affected kinases. KINOMEscan is based on a competition reaction that quantitatively measures the ability of a test compound to compete with an active sitedirected ligand for binding to the kinase active site. Binding reactions were performed using DNA-tagged kinases, immobilized affinity ligand and TBPT in binding buffer (20\% SeaBlock, $0.17 \times$ PBS, $0.05 \%$ Tween 20 and $6 \mathrm{mM} \mathrm{DTT}$ ) at RT. After the assay plates were incubated with shaking for $1 \mathrm{~h}$, the liganded beads were washed with washing buffer ( $1 \times$ PBS and $0.05 \%$ Tween 20). Then, the beads were re-suspended in elution buffer (1 $1 \times$ PBS, $0.05 \%$ Tween 20 , and $0.5 \mu \mathrm{M}$ ligand) and incubated with shaking for $30 \mathrm{~min}$. The kinase concentration in the eluates was measured via qPCR. The results are represented as '\%Ctrl', which was calculated using the following formula: (test compound signal-positive control signal)/(DMSO signal-positive control signal) $\times 100 \%$. A lower $\%$ Ctrl indicates stronger binding to the kinase active site.

Statistical analysis. Data are expressed as the mean \pm S.D. The statistical significance was tested using an unpaired two-tailed Student's $t$-test. $P$-values $<$ 0.05 were considered to indicate statistically significant differences.

\section{Conflict of Interest}

The authors declare no conflict of interest.

Acknowledgements. This work was supported by the Strategic Priority Research Program of the Chinese Academy of Sciences (XDB14030401) and Natural Science Foundation of Shandong Province (ZR2014BM026 and ZR2013BQ026).

1. Gottesman MM, Fojo T, Bates SE. Multidrug resistance in cancer: role of ATP-dependent transporters. Nat Rev Cancer 2002; 2: 48-58.

2. Green DR, Evan GI. A matter of life and death. Cancer Cell 2002; 1: 19-30.

3. Hedigan K. Cancer: herbal medicine reduces chemotherapy toxicity. Nat Rev Drug Disc 2010; 9: 765-765

4. Kaelin WG. The concept of synthetic lethality in the context of anticancer therapy. Nat Rev Cancer 2005; 5: 689-698.

5. Moitra K, Lou H, Dean M. Multidrug efflux pumps and cancer stem cells: insights into multidrug resistance and therapeutic development. Clin Pharmacol Ther 2011; 89: 491-502.

6. Longley D, Johnston P. Molecular mechanisms of drug resistance. J Pathol 2005; 205: 275-292.

7. Kartner N, Ling V. Cell surface P-glycoprotein associated with multidrug resistance in mammalian cell lines. Science 1983; 221: 1285-1288.

8. Gottesman MM, Fojo T, Bates SE. Multidrug resistance in cancer: role of ATP-dependent transporters. Nat Rev Cancer 2002; 2: 48-58.

9. Teodori E, Dei S, Martelli C, Scapecchi S, Gualtieri F. The functions and structure of ABC transporters: implications for the design of new inhibitors of Pgp and MRP1 to control multidrug resistance (MDR). Curr Drug Targets 2006; 7: 893-909.

10. Chaudhary PM, Roninson IB. Expression and activity of P-glycoprotein, a multidrug efflux pump, in human hematopoietic stem cells. Cell 1991; 66: 85-94.

11. Arndt CA, Stoner JA, Hawkins DS, Rodeberg DA, Hayes-Jordan AA, Paidas CN et al. Vincristine, actinomycin, and cyclophosphamide compared with vincristine, actinomycin, and cyclophosphamide alternating with vincristine, topotecan, and cyclophosphamide for intermediate-risk rhabdomyosarcoma: children's oncology group study D9803. J Clin Oncol 2009; 27: 5182-5188.

12. Ruymann FB, Newton WA Jr., Ragab AH, Donaldson MH, Foulkes M. Bone marrow metastases at diagnosis in children and adolescents with rhabdomyosarcoma. A report from the intergroup rhabdomyosarcoma study. Cancer 1984; 53: 368-373.

13. Depierre A, Milleron B, Moro-Sibilot D, Chevret S, Quoix E, Lebeau B et al. Preoperative chemotherapy followed by surgery compared with primary surgery in resectable stage I (except T1NO), II, and Illa non-small-cell lung cancer. J Clin Oncol 2002; 20: 247-253.

14. Hurria A, Togawa K, Mohile SG, Owusu C, Klepin HD, Gross CP et al. Predicting chemotherapy toxicity in older adults with cancer: a prospective multicenter study. J Clin Oncol 2011; 29: 3457-3465.

15. Chung MH, Kiarie JN, Richardson BA, Lehman DA, Overbaugh J, Kinuthia J et al. Highly active antiretroviral therapy (HAART) versus zidovudine/nevirapine effects on early breast milk HIV-1 RNA: a phase II randomized clinical trial. Antiviral Ther 2008; 13: 799.

16. Kawasuji T, Johns BA, Yoshida H, Weatherhead JG, Akiyama T, Taishi T et al. Carbamoyl pyridone HIV-1 integrase inhibitors. 2. Bi- and tricyclic derivatives result in superior antiviral and pharmacokinetic profiles. J Med Chem 2013; 56: 1124-1135.

17. Jahchan NS, Dudley JT, Mazur PK, Flores N, Yang D, Palmerton A et al. A drug repositioning approach identifies tricyclic antidepressants as inhibitors of small cell lung cancer and other neuroendocrine tumors. Cancer Disc 2013; 3: 1364-1377.

18. Xu X, Guo S, Dang Q, Chen J, Bai X. A new strategy toward fused-pyridine heterocyclic scaffolds: bischler-Napieralski-type cyclization, followed by sulfoxide extrusion reaction. J Combinatorial Chem 2007; 9: 773-782. 
19. Teraishi F, Wu S, Sasaki J, Zhang L, Zhu H-B, Davis JJ et al. P-glycoprotein-independent apoptosis induction by a novel synthetic compound, MMPT [5-[(4-methylphenyl) methylene]2-(phenylamino)-4 (5H)-thiazolone]. J Pharmacol Exp Ther 2005; 314: 355-362.

20. Zhang C, Zhai S, Li X, Zhang Q, Wu L, Liu Y et al. Synergistic action by multi-targeting compounds produces a potent compound combination for human NSCLC both in vitro and in vivo. Cell Death Dis 2014; 5: e1138.

21. Zhang Q, Zhai S, Li L, Li X, Zhou H, Liu A et al. Anti-tumor selectivity of a novel tubulin and HSP90 dual-targeting inhibitor in non-small cell lung cancer models. Biochem Pharmacol 2013; 86: 351-360.

22. Maemondo M, Inoue A, Kobayashi K, Sugawara S, Oizumi S, Isobe H et al. Gefitinib or chemotherapy for non-small-cell lung cancer with mutated EGFR. N Engl J Med 2010; 362: 2380-2388

23. Hanna N, Shepherd FA, Fossella FV, Pereira JR, De Marinis F, von Pawel J et al. Randomized phase III trial of pemetrexed versus docetaxel in patients with non-small-cell lung cancer previously treated with chemotherapy. J Clin Oncol 2004; 22: 1589-1597.

24. Mitsudomi T, Morita S, Yatabe Y, Negoro S, Okamoto I, Tsurutani J et al. Gefitinib versus cisplatin plus docetaxel in patients with non-small-cell lung cancer harbouring mutations of the epidermal growth factor receptor (WJTOG3405): an open label, randomised phase 3 trial. Lancet Oncol 2010; 11: 121-128.

25. Boulton DW, DeVane CL, Liston HL, Markowitz JS. In vitro P-glycoprotein affinity for atypical and conventional antipsychotics. Life Sci 2002; 71: 163-169.

26. Garrigues A, Nugier J, Orlowski S, Ezan E. A high-throughput screening microplate test for the interaction of drugs with P-glycoprotein. Anal Biochem 2002; 305: 106-114.

27. Agarwal S, Pal D, Mitra AK. Both P-gp and MRP2 mediate transport of Lopinavir, a protease inhibitor. Int J Pharm 2007: 339: 139-147.

28. Greiner B, Eichelbaum M, Fritz P, Kreichgauer HP, Von Richter O, Zundler J et al. The role of intestinal P-glycoprotein in the interaction of digoxin and rifampin. J Clin Invest 1999; 104: 147-153.

29. Wang Z, Chen J, Wang J, Ahn S, Li C-M, Lu Y et al. Novel tubulin polymerization inhibitors overcome multidrug resistance and reduce melanoma lung metastasis. Pharm Res 2012; 29: 3040-3052

30. Chang J-Y, Chang C-Y, Kuo C-C, Chen L-T, Wein Y-S, Kuo Y-H. Salvinal, a novel microtubule inhibitor isolated from Salvia miltiornizae Bunge (Danshen), with antimitotic activity in multidrug-sensitive and -resistant human tumor cells. Mol Pharmacol 2004; 65: 77-84.

31. Chen J, Ahn S, Wang J, Lu Y, Dalton JT, Miller DD et al. Discovery of novel 2-aryl-4-benzoylimidazole (ABI-III) analogues targeting tubulin polymerization as antiproliferative agents. J Med Chem 2012; 55: 7285-7289.

32. Bacher G, Nickel B, Emig P, Vanhoefer U, Seeber S, Shandra A et al. D-24851, a novel synthetic microtubule inhibitor, exerts curative antitumoral activity in vivo, shows efficacy toward multidrug-resistant tumor cells, and lacks neurotoxicity. Cancer Res 2001; 61: 392-399.

33. Chauhan R, Madan J, Kaushik D, Sardana S, Pandey RS, Sharma R. Inclusion complex of colchicine in hydroxypropyl- $\beta$-cyclodextrin tenders better solubility and improved pharmacokinetics. Pharm Dev Technol 2013; 18: 313-322.

34. Jackson JR, Patrick DR, Dar MM, Huang PS. Targeted anti-mitotic therapies: can we improve on tubulin agents? Nat Rev Cancer 2007: 7: 107-117.

35. Marupudi NI, Han JE, Li KW, Renard VM, Tyler BM, Brem H Paclitaxel: a review of adverse toxicities and novel delivery strategies. Expert Opin Drug Saf 2007; 6: 609-621.

36. Risinger AL, Giles FJ, Mooberry SL. Microtubule dynamics as a target in oncology. Cancer Treat Rev 2009; 35: 255-261.

37. Finkelstein Y, Aks SE, Hutson JR, Juurlink DN, Nguyen P, Dubnov-Raz G et al. Colchicine poisoning: the dark side of an ancient drug. Clin Toxicol 2010; 48: 407-414.

38. Jordan MA, Thrower D, Wilson L. Effects of vinblastine, podophyllotoxin and nocodazole on mitotic spindles. Implications for the role of microtubule dynamics in mitosis. J Cell Sci 1992; 102: $401-416$

39. Frankel A, Buckman R, Kerbel RS. Abrogation of taxol-induced G2-M arrest and apoptosis in human ovarian cancer cells grown as multicellular tumor spheroids. Cancer Res 1997; 57: 2388-2393.

40. Mollinedo F, Gajate C. Microtubules, microtubule-interfering agents and apoptosis Apoptosis 2003; 8: 413-450.

41. Pellegrini F, Budman DR. Review: tubulin function, action of antitubulin drugs, and new drug development. Cancer Invest 2005; 23: 264-273.

42. Jordan MA. Mechanism of action of antitumor drugs that interact with microtubules and tubulin. Curr Med Chem Anti-Cancer Agents 2002; 2: 1-17.

43. Perez EA. Microtubule inhibitors: differentiating tubulin-inhibiting agents based on mechanisms of action, clinical activity, and resistance. Mol Cancer Ther 2009; 8 : 2086-2095.

44. Jordan MA, Wilson L. Microtubules as a target for anticancer drugs. Nat Rev Cancer 2004; 4 253-265

45. Li F, Ambrosini G, Chu EY, Plescia J, Tognin S, Marchisio PC et al. Control of apoptosis and mitotic spindle checkpoint by survivin. Nature 1998; 396: 580-584.

46. Yang J-S, Hour M-J, Huang W-W, Lin K-L, Kuo S-C, Chung J-G. MJ-29 inhibits tubulin polymerization, induces mitotic arrest, and triggers apoptosis via cyclin-dependent kinase 1 mediated Bcl-2 phosphorylation in human leukemia U937 cells. J Pharmacol Exp Ther 2010; 334: $477-488$.
47. Denning DP, Hirose T. Anti-tubulins DEPendably induce apoptosis. Nat Cell Biol 2014; 16: $741-743$

48. Poruchynsky MS, Komlodi-Pasztor E, Trostel S, Wilkerson J, Regairaz M, Pommier Y et al. Microtubule-targeting agents augment the toxicity of DNA-damaging agents by disrupting intracellular trafficking of DNA repair proteins. Proc Natl Acad Sci USA 2015; 112: 1571-1576.

49. Srivastava M, Raghavan SC. DNA double-strand break repair inhibitors as cancer therapeutics. Chem Biol 2015; 22: 17-29.

50. Liebler DC, Guengerich FP. Elucidating mechanisms of drug-induced toxicity. Nat Rev Drug Disc 2005; 4: 410-420.

51. Lounkine E, Keiser MJ, Whitebread S, Mikhailov D, Hamon J, Jenkins JL et al. Large-scale prediction and testing of drug activity on side-effect targets. Nature 2012; 486 : 361-367.

52. Funhoff R, Zamurovic N, Vicart A, Bouchez L, Voshol H, Gerrits B et al. Identification of offtarget binding proteins to elucidate mechanism of drug toxicity. Toxicol Lett 2012; 211: S113-S114.

53. Abassi YA, Xi B, Zhang W, Ye P, Kirstein SL, Gaylord MR et al. Kinetic cell-based morphological screening: prediction of mechanism of compound action and off-target effects. Chem Biol 2009; 16: 712-723.

54. Manning G, Whyte DB, Martinez R, Hunter T, Sudarsanam S. The protein kinase complement of the human genome. Science 2002; 298: 1912-1934

55. Force T, Krause DS, Van Etten RA. Molecular mechanisms of cardiotoxicity of tyrosine kinase inhibition. Nat Rev Cancer 2007; 7: 332-344.

56. Hasinoff BB, Patel D, O'Hara KA. Mechanisms of myocyte cytotoxicity induced by the multiple receptor tyrosine kinase inhibitor sunitinib. Mol Pharmacol 2008; 74: 1722-1728.

57. Kumar R, Crouthamel M, Rominger D, Gontarek R, Tummino P, Levin R et al. Myelosuppression and kinase selectivity of multikinase angiogenesis inhibitors. Br J Cancer 2009; 101: 1717-1723.

58. Karaman MW, Herrgard S, Treiber DK, Gallant P, Atteridge CE, Campbell BT et al A quantitative analysis of kinase inhibitor selectivity. Nat Biotechnol 2008; 26: 127-132.

59. Mu Y, Liu Y, Li L, Tian C, Zhou H, Zhang $Q$ et al. The novel tubulin polymerization inhibitor MHPT exhibits selective anti-tumor activity against rhabdomyosarcoma in vitro and in vivo. PloS One 2014; 10: e0121806-e0121806.

60. Huber KV, Salah E, Radic B, Gridling M, Elkins JM, Stukalov A et al. Stereospecific targeting of MTH1 by (S)-crizotinib as an anticancer strategy. Nature 2014; 508: 222-227.

61. Park BS, Al-Sanea MM, Abdelazem AZ, Park HM, Roh EJ, Park H-M et al. Structure-based optimization and biological evaluation of trisubstituted pyrazole as a core structure of potent ROS1 kinase inhibitors. Bioorg Med Chem 2014; 22: 3871-3878.

62. Wu B, Wang H-L, Cee VJ, Lanman BA, Nixey T, Pettus L et al. Discovery of 5-(1H-indol-5-yl)1,3,4-thiadiazol-2-amines as potent PIM inhibitors. Bioorg Med Chem Lett 2015; 25 : $775-780$.

63. Gottesman MM. Mechanisms of cancer drug resistance. Ann Rev Med 2002; 53: 615-627.

64. Vichai V, Kirtikara K. Sulforhodamine B colorimetric assay for cytotoxicity screening. Nat Protocols 2006; 1: 1112-1116.

65. Liu Y, Li F, Wu L, Wang W, Zhu H, Zhang $Q$ et al. Improving both aqueous solubility and anticancer activity by assessing progressive lead optimization libraries. Bioorg Med Chem Lett 2015; 25: 1971-1975.

66. Zhai S, Yang L, Cui QC, Sun Y, Dou QP, Yan B. Tumor cellular proteasome inhibition and growth suppression by 8-hydroxyquinoline and clioquinol requires their capabilities to bind copper and transport copper into cells. J Biol Inorg Chem 2010; 15: 259-269.

67. Obach RS. Prediction of human clearance of twenty-nine drugs from hepatic microsomal intrinsic clearance data: an examination of in vitro half-life approach and nonspecific binding to microsomes. Drug Metab Dispos 1999; 27: 1350-1359.

68. Kariv I, Cao H, Oldenburg KR. Development of a high throughput equilibrium dialysis method. J Pharm Sci 2001; 90: 580-587.

69. McGinnity DF, Soars MG, Urbanowicz RA, Riley RJ. Evaluation of fresh and cryopreserved hepatocytes as in vitro drug metabolism tools for the prediction of metabolic clearance. Drug Metab Dispos 2004; 32: 1247-1253.

70. Di L, Kerns EH, Hong Y, Chen H. Development and application of high throughput plasma stability assay for drug discovery. Int J Pharm 2005; 297: 110-119.

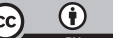

Cell Death and Disease is an open-access journal published by Nature Publishing Group. This work is licensed under a Creative Commons Attribution 4.0 International License. The images or other third party material in this article are included in the article's Creative Commons license, unless indicated otherwise in the credit line; if the material is not included under the Creative Commons license, users will need to obtain permission from the license holder to reproduce the material. To view a copy of this license, visit http://creativecommons.org/licenses/by/4.0/ 